\title{
Linguistics in the service of communication disorders
}

\section{New frontiers}

\author{
Dorit Ravid ${ }^{1,2}$, Amalia Bar-On ${ }^{2}$ and Elitzur Dattner ${ }^{3}$ \\ ${ }^{1}$ School of Education, Tel Aviv University / ${ }^{2}$ Department of Communication \\ Disorders, Tel Aviv University / ${ }^{3}$ Linguistics Department, Tel Aviv University
}

\begin{abstract}
Linguistics and Communication Disorders are considered two different disciplines by most students and scholars in both fields as well as by researchers working in other relevant fields such as psychology and education. However, most core disorders, disabilities and delays in communicative ability directly concern language, especially in conjunction with human development from infancy to adulthood, but also as related to the loss of communicative skills in the aging brain. Linguistics thus emerges as a major source of scientific insights and practical applications for the field of communication disorders. While it is obviously impossible to account for the diverse and sometimes contradictory views of linguistics in a single paper, we nonetheless focus on the contribution of novel linguistic and psycholinguistic approaches to the current conceptualization of communication disorders from different perspectives. We first discuss the nature of evidence and research methods in the two disciplines, with the current usage-based and typological approaches to corpus linguistics as a case in point. Consequently, we discuss the interface of linguistics and communication disorders through four contexts which are considered infelicitous to language acquisition and processing. These are, as follows: (i) hearing loss, (ii) language impairment and dyslexia, (iii) growing up in a low socio-economic environment, and (iv) situations of bilingualism.
\end{abstract}

\section{Introduction}

Communication Disorders is a clinical profession aimed at facilitating language, speech, hearing and oral motor functions by diagnosis, treatment and therapy. In the last few decades, the domain of Communication Disorders has grown exponentially and has come to encompass much more than audiology, speech impediments and early language impairment. A variegated array of impairments is now considered under the scope of Communication Disorders (henceforth: $C D$ ) in addition to speech and voice impediments, constituting of the full range of developmental language disorders from structural to lexical and pragmatic, with much focus on discourse, reading, writing, and arithmetic impairments. In the same way that innovative research in child and adolescent development, executive control, attention and memory functions are brought to the attention of $\mathrm{CD}$ experts, they find new frontiers in linguistics of ultimate interest and relevance to their work.

The role of language in $\mathrm{CD}$, based on the realization that most developmental and learning disorders are language-based or language-related, is evidenced by the numerous studies 
encompassing every facet of linguistic knowledge in thematic disorders journals such as American Journal of Speech-language Pathology, Communication Disorders Quarterly, Journal of Communication Disorders, Language Speech and Hearing Services in Schools, The International Journal of Language \& Communication Disorders, or Topics in Language Disorders - to name a few. At the same time, language and communications disabilities, side by side with atypical linguistic development and processing, occupy a fair share of language-oriented journals (e.g., Brain and Language, Journal of Memory and Language, Journal of Speech, Language and Hearing Research, Language and Cognitive Processes, or Reading and Writing) and of journals specializing in language acquisition (e.g. Journal of Child Language, First Language, or Language, Interaction and Acquisition) - as well as cognitionoriented, non-thematic journals such as Cognition, Cognitive Science, Trends in Cognitive Sciences or Developmental Science. The central role spoken and written language, discourse and literacy now occupy in CD research underscores the value of linguistic science to providing solutions for cognitive, developmental and learning issues in clinical and educational contexts.

Since most core disorders directly concern language, especially in conjunction with human development from infancy to adulthood and onwards in the aging brain, linguistics emerges as a major source of scientific insights for the theoretical understanding of communicative disorders, and of application in the practice of CD practitioners - Speech/Language Pathologists (SLPs). Consequently, SLPs and their trainers are now aware that linguistic knowledge is crucial for the identification, diagnosis and therapy of a broad range of disabilities across the life span. Indeed, a glance at any of the current curricula in CD departments of major universities reveals to what extent this need for a robust linguistic, psycholinguistic, neurolinguistic, and sociolinguistic foundation for SLPs is attended to. Linguistics is definitely regarded as indispensable for the understanding and treatment of communication disabilities at different stages of human development and in various social and communicative contexts. Against this background, the current paper intends to shed light on the contribution of linguistics to $\mathrm{CD}$ while taking into account differences in the motivation and methods for studying language, its acquisition and processing. Given the versatile and even contradictory views of language and its processing currently held by linguists themselves, as well as their interface with other domains (such as psycholinguistics, sociolinguistics, neurolinguistics) we take a neutral and inclusive view of "language" and "linguistics" in discussing their applications to $\mathrm{CD}$. We thus highlight diverse facets of the sciences of language as they become relevant to different requirements of $\mathrm{CD}$ researchers.

\section{Methodological issues}

Despite their shared interest in language and communication, linguistics and CD are motivated and informed by different theoretical and applied approaches to these domains. While linguistic scholarship is motivated by the wish to gain insights about the nature of linguistic knowledge and processing, CD science is interested in gaining information about language and communication impairments, identifying their patterns and using linguistic knowledge to treat them.

One domain of difference between the two cultures of linguistics and communication disorders is in the nature of what is considered as research methodology and the nature of scientific evidence, which essentially comes down to the difference between empirical research and structured introspection (Goodluck and Zweig, 2013; Kertész and Rákosi, 2012). As in the social and health sciences, the underpinnings of CD is empirical, based on the assumption that knowledge arises from human experience and that formulating and testing hypotheses which lead to valid conclusions require data acquired by direct observation or experience. This means reliance on proper designs with successful control over extraneous variables, meeting behavioral criteria of reliability, validity and replicability to ensure the credibility of empirical research, as well as using well-motivated 
analytic methods (qualitative or quantitative) which allow the interpretation of the data (Goodwin, 2005). At the same time, it is recognized by CD scholars that linguistic theory can inform research design, provide hypotheses about disorders, contribute to data interpretation and explain its clinical implications. CD experts rely on linguistics to provide the answers to theoretical questions about the nature of language, its structure and functions, language origins and change, how it is encoded in the brain, as well as questions of its acquisition, knowledge, and processing in humans. Thus, different theoretical linguistic frameworks and changes in linguistic theories have influenced SLPs' approaches to diagnostics and therapy. For example, treating children's innovative errors such as holded or mouses as signs of linguistic development rather than mistakes that need to be eradicated derives from the basic insights in the linguistic study of first (and second) language acquisition that errors indicate a state of linguistic knowledge and development.

Linguistic methodology itself has undergone great changes at the same time, which has brought linguistic approaches closer to CD methodological criteria. Chomsky (1985) set the goal of linguistics as an explanation of speakers' ability to extend their limited linguistic experience to new acceptable forms, based on the assumption that human linguistic competence makes it possible to judge sentences as grammatical or ungrammatical. As grammar was conceived as a mental construct, the mainstream method of inquiry into data in linguistics was informally gathered acceptability judgments by individual respondents, most often linguists (Phillips 2010; Schütze 2011a,b). The last decade has however seen some doubt cast regarding what psychologists and linguists came to call the 'weak empirical foundation' of theories (such as Universal Grammar or syntactic movement) based on intuitive and metacognitive grammaticality judgments (Edelman \& Christianson 2003; Evans \& Levinson 2009). Linguists became aware of cognitive and cultural sources of sentences' acceptability beyond their grammaticality (Bresnan 2007; Hofmeister et al. 2013), and of the unstable and contextual nature of such judgments (McClelland et al. 2010). Currently, while some researchers advocate the adoption of canonical empirical methods for data collection and analysis (Gibson \& Fedorenko 2013), others discuss the limitations of quantitative methodology (Phillips 2010) and present evidence for the reliability of traditional linguistic methodology (Sprouse \& Almeida 2013, Sprouse, Schütze \& Almeida 2013). The consensus seems to be that given the multiple mechanisms involved in language use, linguists should be encouraged to test theories in psycholinguistically sound ways without giving up reliance on key linguistic insights (Piantadosi \& Gibson in press; Tily \& Jaeger 2011).

\section{Contributions of linguistics to $\mathrm{CD}$ science}

One major domain where linguistic research interests coincide with those of CD involves the interface of language and cognition. Specifically, they are both concerned with questions such as whether and to what extent language is independent of other cognitive systems and / or guided by universal properties, the relationship between conceptual and linguistic acquisition and knowledge in different languages, and the role of memory and frequency in language evolution, processing and learning (Bybee 2006; Carruthers 2008; Harris 2003). This relationship is an inherent issue in the ongoing debate between linguistic theories and approaches regarding the question of modularity of mind and the existence of hard-wired language-dedicated systems (Berwick, Pietroski, Yankama \& Chomsky 2011; Cinque 2013; Slobin 1996). The current status of linguistic thought, most especially the debate about the language / cognition interface, informs CD research and practice in both research design and its application (Friedmann 2013; Joanisse \& Seidenberg, 1998). CD leaders consider it critical for SLPs to gain an understanding of how language knowledge is structured and of the bases of language disorders (Bishop \& Norbury 2008; Jarmulowicz \& Taran 2013). In fact, what drives diagnosis and therapy of $\mathrm{CD}$ is current research about the nature, structure and interaction of grammar and 
lexicon as well as how they relate to general cognitive processes (McArthur, Ellis \& Atkinson 2009; van der Lely 2005). Clearly, CD researchers, like psychologists, rely on linguistic-generated insights as the evidence-based scientific framework against which language disabilities are captured and clinical solutions sought.

In the wake of recent debates in the linguistic world relating to what exactly the human adaptation in language is, the nature of the language and cognition interface, and the construal of innateness in language acquisition, more connections can now be pointed out between language analysis and its clinical applications. CD professionals and practitioners have always assumed that knowledge arises from experience and have sought ways not only to diagnose and treat the disorder but also to explain its cognitive and neurological sources. The changes in linguistic theory from the perception of language as a narrow grammatical faculty to its construal as a broadly based cognitive faculty have brought about a concurrent shift in CD science: Rather than seeking the specific source of a deficit or a disorder (e.g., auditory or grammatical bases of language impairment), CD researchers now regard them as deriving from a language-learning disability (Bishop 2009).

Current usage-based models of language structure and use, deriving from the Cognitive Linguistics tradition (Lakoff 1991; Langacker 1987), assume language knowledge to be a non-autonomous cognitive faculty (Croft \& Cruse 2004), and thus extremely sensitive to other cognitive domains. This approach encourages SLPs to broaden treatment from language structure to its use in different communicative contexts. Usage based theories regard linguistic acquisition as a data-driven, bottom-up task strongly leaning on mind-reading socio-cognitive abilities on the one hand, and the changing nature of linguistic input, on the other (Rowland et al. 2012; Tomasello 2003). Thus, it is extremely important for CD researchers and SLPs to gain information about patterns of use in naturally occurring language, from morpho-phonology through syntax to discourse structures and their functions, so as to base study design and subsequent treatment on real data. Fortunately, Corpus Linguistics approaches to language analysis provide such solutions through analyzing large scale corpora containing both frequent, conventional patterns, and less frequent, novel uses of language - making it possible for SLPs to set goals for both oral and literate language gains. The analyses conducted are statistically based, taking the corpus to be a representation of one's experience with language (Bybee 2010; Gries \& Stefanowitsch 2007), making it possible to account for the role of memory and frequency in all aspects of language. Evidence-based features of produced discourse, when used in systematic research, can be immensely helpful in the diagnosis and treatment of disorders (Berman \& Ravid 2008; McNamara, Crossley \& McCarthy 2010). For example, Berman and Ravid (2008) showed that the ability to produce expository texts emerges around the 7 th grade and thus becomes a useful tool for the assessment of writing abilities around high-school age.

One of the merits of corpus linguistics is that it allows the comparison of usage patterns of the same conceptual space in a variety of languages, thus accounting for the diversity of languages in a typological perspective, with immense benefits for psychological, clinical and educational applications. Typology, in linguistics, is the search for patterns "that occur systematically across languages" (Croft 2003:1) with the goal of reaching genuine typological generalizations. Linguistic thinking has long been dominated by the specific properties of English, which are not necessarily shared by the world's languages (Chung 2009; Evans \& Levinson 2009; Haspelmath 2012). However, from a communication disorders perspective, the typology of a language has been found to be crucial for the understanding of language development and language disorders (Berman \& Slobin 1994; Ravid, Levie \& Avivi Ben-Zvi 2003). Specifically, typological structure has been shown to account for the severity of morphological impairment in languages of differential morphological complexity (Dromi, Leonard \& Shteiman 1993). In the same way, the study of the characteristics of orthographies other than English in conjunction with phonological and grammatical structures 
of languages in possession of these orthographies has contributed immensely to theories and application of reading, writing and spelling (Frost 2012; Share 2008) in the last decades (see review in Ravid 2012).

Given the experience-based approach to learning prevalent in CD, it is no wonder that it finds great advantages in technological advancements which provide highly sophisticated tools and bettergrounded, finer grained analyses of ambient language (Graesser \& McNamara 2011). CD researchers can now make use of advanced statistical methods to investigate the role of frequency in language, such as Multidimensional Scaling (Baayen 2008) and Multiple Correspondence Analysis (Levshina, Geeraerts \& Speelman 2013). For example, Dattner (in preparation) has shed light on the role the typologically specific system of the Hebrew verb conjugations (the binyan system) plays in structuring conceptual spaces in Dative constructions. This will make it possible for Israeli SLPs to construct meaningful treatment of Hebrew syntax in conjunction with its rich derivational morphology.

Corpus linguistics has made another kind of impact on the scope and breadth of knowledge required of SLPs in treating language and communication disorders, which is the domain of written discourse in later language development.

\section{Written discourse}

Written text production has been considered outside the domain of both core linguistics and CD in the not so recent past, but is gaining importance and significance in both domains. The early Saussurean reaction of linguistic science to previous philological preoccupation with written texts of dead languages pointed at spoken language, the hallmark of humanity, as the natural, direct, uncontrived and 'real' linguistic phenomenon. In contrast, written language was regarded as merely a written shadow of 'real language' - in fact, no more than a mirror, the transcription of oral production. This placed the study of written language squarely outside the domain of linguistic analysis seeking to achieve theoretical insight. Given the close attention CD specialists have always paid to arenas of linguistic concerns, their focus too has been on oral language disabilities or on grammatical deficits rather than on problems in written text production, which were relegated to educators. But the psycholinguistic investigation of how language users learn to control and shape the flow of information in written discourse through linguistic means has now been shown to lead to important insights about language structure, use and development (Berman, 2005; Ravid, 2005; Sun \& Nippold, 2012).

Evidence points to skilled writers being able to construct coherent texts with longer and denser information packages in hierarchically complex syntactic constructions (Ravid in press; Ravid \& Berman, 2010) which can be re-read, reviewed and revised by readers within their context without the pressures of on-line processing (Berman \& Ravid, 2008; Ravid \& Tolchinsky, 2002). This enables researchers to investigate the elusive concept of "syntactic complexity" in the context or writing. Writing moreover encourages the retrieval of higher-register, literate lexical items, and marked morpho-syntactic structures (Ravid \& Berman 2009; Ravid \& Levie 2010). At the same time, these very same features impose a greater burden on less experienced writers such as children, who still lack the executive functions for monitoring large pieces of text, especially in expository writing (Berman 2008). It is even harder for children to construct a linguistic space within which both spoken and written modalities can be simultaneously and appropriately accessed (Berman \& Nir-Sagiv 2010; Ravid 2006).

These features of written discourse make it an appropriate context for the evaluation of later language development, a period of intense linguistic development taking place during the school years - ages 5 to young adulthood (Berman 2004; Nippold 2007; Ravid, Dromi \& Kotler 2009). During this period, the cognitive and linguistic demands of written text construction (and comprehension) exacerbate the problems of children with language impairment, reading and writing 
disabilities and children with poor SES background, which stand out even more during the school years (Berman, Nayditz \& Ravid 2011; Williams, Larkin \& Blaggan 2013). Many language disabilities are thus manifested in this age group as dyslexia and learning disabilities, and require the attention of expert CD professionals. Linguistic analyses of texts of different genres written by children and adolescents with developmental and language disorders reveal academic weaknesses and relations with other linguistic abilities and thus pinpoint areas for remedial therapy and improvement (Mackie, Dockrell \& Lindsay 2013; Nippold, Mansfield, Billow \& Tomblin 2009). At the same time, analyses of written discourse can be of great value to linguists and psycholinguists in their search for an understanding of how the structure of language interfaces with its different modalities and discourse functions (Strömqvist \& Verhoeven 2004).

\section{The linguistics / disorders interface}

Having established the relevance of linguistic theory, methodology and scope to the study of language learning and disorders, the next section examines the contribution of linguistic science to the understanding, identification and treatment of four language / communication disorders which all share less than felicitous conditions of language learning. Clearly, adequate learning conditions are necessary for children to develop language proficiently. This is because neuroplasticity - the ability of the brain to adapt to current contingencies - is at its highest in early childhood, permitting the reorganization of neural pathways and architecture (Stiles et al. 2012) at a time when a native tongue is learned in close conjunction with maternal care. During this crucial period, children need to have access to linguistic input that is both quantitatively and qualitatively appropriate to enable the coherent category formation, which is essential to generalization and consolidation of language knowledge (Gathercole \& Hoff 2007).

In this context, two types of inadequate learning conditions are likely to impair optimal language development in the early stages, and to impinge negatively on the subsequent acquisition of literacy at school age. One of these conditions is a function of perceptual and cognitive factors internal to the individual which prevent them from taking maximal advantage of the linguistic input in their environment. In relation to the infelicitous learning conditions introduced above, these are the cases of (i) children suffering from hearing loss and (ii) language impairment and dyslexia. A second type of inadequate learning condition is rooted in external socio-economic environmental factors (infelicitous condition iii), where paucity in linguistic input puts at risk the optimal achievement of language and literacy skills from early childhood onwards. This is the widely-researched condition of children growing up in low socio-economic situations. In contrast to these language disorders and less than ideal contextual learning conditions, we refer to a communicative setting which, though eventually beneficial to language and cognitive development, raises interesting issues of language growth and consolidation which are relevant in the current context - bi- and multilingualism (condition iv).

\section{Hearing loss}

Speech perception is critical for picking up the phonological, lexical and morpho-syntactic patterns of a language (Houston 2002), and thus it requires massive exposure to linguistic input. Therefore, children born with congenital deafness are at grave risk regarding the acquisition and development of spoken and written language (Coppens et al. 2013). Linguistic science has made important contributions to the preservation or restoration of the auditory system in cases of prelingual hearing impairment, where developing neural organization related to speech perception is affected by auditory deprivation. One example is the way language sampling, storage and analysis technology combined with hospital-based newborn hearing screening programs now result in the earlier referral, 


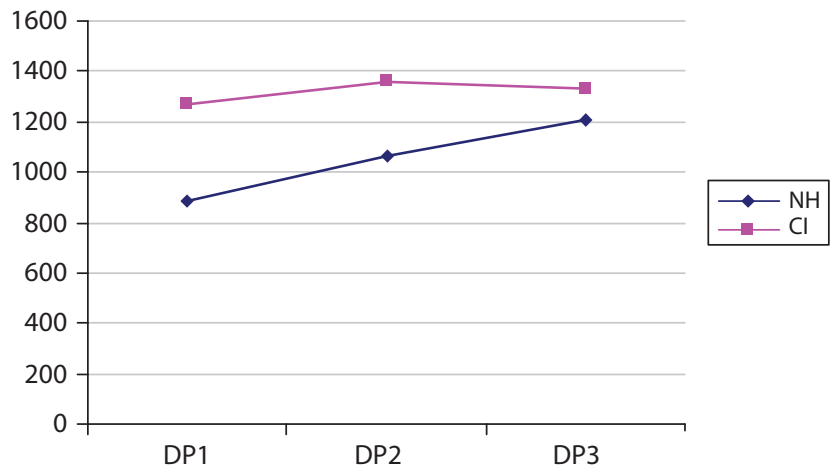

Figure 1. Median of open and closed-class tokens at each data point ((1) $1 ; 10-2 ; 0 ;(2) 2 ; 1-2 ; 3 ;(3) 2 ; 4-2 ; 5)$ in normally hearing and implanted children, by hearing age (Herzberg 2010)

diagnosis, and treatment of deaf infants and children. Such screening programs are positively related to measures of expressive and receptive language (vocabulary size and quality, standardized phonological inventories, speech intelligibility) and better language outcomes at school age (Nelson et al. 2008). Another contribution relates to the cooperation of linguists, psycholinguists and CD professionals in cochlear implantations, which expose the deaf child's auditory system to a quality of sound experience not available with hearing aids alone. In cases of profound hearing loss from $90 \mathrm{~dB}$ and above, most outer hair cells in the cochlea are absent or dysfunctional, so that hearing aids do not provide the necessary sensory information for speech perception and comprehension or the auditory feedback needed for speech production and language learning. Prior to the advent of the cochlear implant in the 1990's, children born with congenital deafness had great difficulty in acquiring their native tongue (Paul \& Quigley 1994), with linguistic gains at half the pace of hearing children (Svirsky 1999). The cochlear implant has revolutionized the rehabilitation of severe to profound hearing loss by transmitting acoustic information through direct electrical stimulation of the auditory nerve, thus bypassing the damaged cochlea and resulting in partial restoration of the frequency resolution of the cochlea (Nicholas \& Geers 2007). Recent studies have shown that when implantation is carried out early on, in the first of life, coupled with appropriate language therapy, improvement can be expected in language acquisition (Schauwers, Gillis \& Govaerts 2008). For example, a study comparing the development of the early Hebrew lexicon in three children with cochlear implants and three normally hearing children (Herzberg 2010) showed that when matched for hearing age (for the implanted children, the time elapsed since implant activation), the CI children had more content and function words than normally hearing children across their early development (Figure 1). This means that the combination of rehabilitative care by SLPs and the degree of speech perception provided by the CI, catapult deaf children into spoken language. These advances could not have been possible without the close cooperation of linguistic experts, providing the phonological, lexical and morpho-syntactic measures for assessing language learning, with CD professionals, responsible for the audiological and therapeutic methods employed to rehabilitate deaf children.

\section{Language impairment}

A second example of language learning under adverse neuro-cognitive conditions is linguistic impairment. Most researchers regard language impairment as a core developmental disability in the domain of CD (Clark \& Kamhi 2010; Paul 2007). Language impairment is characterized by a later 
onset and slower pace of language development than in children without deficits, with continuing problems in language comprehension and / or production and in the acquisition of literacy skills (Bishop \& Norbury 2008; Nippold 2007). Research shows that children with language impairment have difficulty in processing various types of linguistic information - phonological, lexical, morphological, syntactic, preventing them from acquiring a large and diverse lexicon. They also find the production and comprehension of extended discourse challenging (Swisher et al, 1995). Once at school, they have difficulty in acquiring command of linguistic literacy, that is, written language skills related to thinking about language (Ravid \& Tolchinsky 2002), of writing and reading, of written text comprehension and text production (Scott \& Windsor 2000).

Side by side as being a central, typical language disorders syndrome, language impairment has been at the center of a linguistic debate for several decades regarding language representation in the mind and in the brain (Leonard \& Deevy 2006). In this case, gaining more knowledge of the disorder would help contribute to a linguistic debate about modularity of mind. The disorder is often termed Specific Language Impairment (SLI), that is, a language disorder in the absence of other primary disorders such as hearing impairment, brain damage, mental retardation, or emotional problems (Leonard 2010), with a discrepancy of about 15 points between verbal and non-verbal IQ (De Villiers 2002; Leonard 2009). If, indeed, LI is SLI, that is specific to language (rather than having implications for or sources in other cognitive systems), and even more specific to particular linguistic systems such as morphological inflection or pragmatics, this would constitute evidence for domain-specificity of language and modularity of mind (Friedmann \& Novogrodsky 2004; Rice \& Wexler, 1996; van der Lely, Jones \& Marshall, 2011). In turn, CD researchers would come up with specific diagnostics and treatment of those areas in language which are supposed to be discretely impaired. Evidence against this conclusion would come from studies indicating that general processing systems underlie language impairment (Joanisse \& Seidenberg 1998; Tallal 2004), from research indicating additional, non-linguistic deficits in individuals with language impairment (Berman \& Ravid 2010; Hill 2001), or from the instability of classification into LI subtypes such as grammatical, lexical or pragmatic impairments (e.g., Conti-Ramsden 1999). If language impairment is indeed coupled with other disorders, more general rehabilitation will be required. Further investigations into the nature of this prevalent language disorder will not only inform therapists (Cirrin \& Gillam 2008) but also contribute towards resolving a major debate in linguistics.

\section{Dyslexia}

Dyslexia is a disorder characterizing individuals with difficulties in learning to read (and spell) that are not related to cognitive impairment. Currently, CD scholars strongly link dyslexia to language impairment, with the two disabilities described as different manifestations of the same underlying problem (Catts 1991) or two disorders that present considerable overlap (Bishop \& Snowling, 2004). Traditionally, however, dyslexia was not considered as a prototypical CD arena. This apparently stems from the fact that over many years dyslexia had been mostly attributed to a visual deficit, as illustrated by the famous phrase coined by Morgan (1896) "congenital word blindness". This is not surprising since the primary sensory system involved in reading is the visual system, and the famous reversal errors regarded as the hallmark of the disability (e.g. reading / writing $b$ for $d$ or was for saw) were perceived as evidence of visual problems (Catts \& Kamhi 1999). Dramatic changes in the approach to dyslexia occurred in the 1970s with the advent of the groundbreaking research of Liberman, Shankweiler and their colleagues suggesting that phonological skills, in particular phonemic awareness, play a crucial role in learning to read (Liberman, Shankweiler, Fisher \& Carter 1974). We know today that phonology is important to reading because writing systems represent spoken language and learning to read in alphabetic systems means mapping graphemes onto phonemes. 
Over the last 30 years a considerable body of studies have supported the importance of phonemic awareness in learning to read and reinforced the concept of phonological-deficit based dyslexia. However, despite these persuasive findings, it is not clear yet if there is indeed a causal link between low phonological awareness and dyslexia, or whether there is a third variable or mechanism influencing both problems (Castles \& Coltheart 2004). Many studies demonstrate various difficulties characterized dyslexic individuals in different ages. Most of them relate to phonological processes such as auditory perception (Gaab et al. 2007; Schulte-Körne et al. 1998) or short-term memory for speech sounds (Berninger et al. 2006). Others report difficulties in (implicit) learning abilities, such as learning sequences of symbols (Gabay, Schiff \& Vakil 2012), or the ability to benefit from stimulus-specific repetitions (Ahissar 2007), supporting the notion of a generally impaired learning mechanism that underlies dyslexia. A large body of research indicates a strong linguistic component in this disorder (Schiff \& Ravid 2007, 2013; Snowling, Gallagher \& Frith 2003).

An interesting relationship between language typology and dyslexia is worth mentioning. While typological studies in the last decade did not contradict the importance of phonology to success in learning to read, they have indicated that the nature of the relationships between them is language-dependent. For one thing, phonological processing is not uniquely important for reading alphabetic orthographies: it is also involved in non-alphabetic systems, however the latter differ from alphabetic systems in the size of the phonological unit that the graphemes or characters activate - either a simple phonological syllable, as in the Japanese Kana, or else syllabic morphemes as in Chinese (Perfetti 2011). Moreover, although alphabetic systems share the grapho-phonemic principle, the specific nature of the sensitivity to word or syllable structure (e.g. dividing the syllable into body-coda or onset-rime units) is affected by the unique phonological and orthographic characters of each language (Share \& Blum 2005). Finally, the transparency of the orthography (i.e., to what extent a written word reliably represents its phonology) dictates the degree of importance of the phonemic awareness to reading (Seymour, Aro \& Eirskine 2003).

In this context, Share (2008:596) notes that "the extreme degree of non-transparency in English has exaggerated the role that phonemic awareness plays in more conventional alphabets and has overshadowed issues that have critical importance across orthographies". One of these issues is the role of language domains other than phonology in reading. It is well known that while writing systems can represent spoken language, they are not mere transcriptions mirroring phonological sequences but rather encode various aspects of the language system such as its morphology and syntax (Derwing 1992). Obviously, in many cases spelling represents morphemic identity rather than phonology (e.g. English -tion) (Deacon \& Kirby 2004; Ravid 2012). Thus, beyond phonological decoding, readers would rely heavily on morpho-orthographic representations in single word recognition. While phonology is mostly needed for unfamiliar word decoding, morphology has an important role in enhancing whole-word recognition in both morphology-rich and poor languages (Bar-On \& Ravid 2011; Carlisle 2000). Moreover, proficient and automatic word recognition is essential for efficient reading, but it is not enough. In Hebrew for example, reading without adherence to the semantico-syntactic context may lead to nonsensical decoding. This is because approximately $25 \%$ of the words in any non-voweled text in Hebrew are homographic (i.e. can be decoded as having different phonological [and meaning] characteristics, as in English wind). Thus, reliance on the grammatical context, especially on morphological structure, is an inherent part of the reading process in Hebrew (Bar-On, 2011). That means that learning to read involves knowledge about the relationship between a writing system and the language it encodes (Perfetti 2003). Even though the investigation of dyslexia and its causes is still under way, informing SLPs of the linguistic processes involved in reading and writing benefits research, diagnosis and therapy of dyslexia in the field of CD. 


\section{Language in low-SES contexts}

In addition to internal, neuro-cognitive obstacles to proficient language and literacy acquisition, external, environmental problems can also hinder optimal language learning. Thus the relevance of linguistics to $\mathrm{CD}$ extends beyond the core disorders discussed above to inadequate learning conditions resulting from external background factors such as socio-economic status (SES) (Chiu \& McBride-Chang 2006). The link between social progress and literacy education has been recognized in social psychology for many years (Bernstein 1960); but since the groundbreaking work of Hart and Risely (1995), robust evidence has pointed to a disadvantage in language and literacy skills of children from poorer, less educated, low SES backgrounds compared with children raised in more favorable circumstances (Bradley \& Corwyn 2002). Such environmental factors have been shown to impede the optimal command of linguistic proficiency (Raviv, Kessenich \& Morrison 2004) and to be detrimental to gaining literacy skills (Aram, Korat \& Levin 2006; McCarthey 1997). Children from less economically established homes and with less educated parents may enter school with a disadvantage (Natriello, McDill \& Pallas 1990; Neuman \& Celano 2001) which is consistently retained in school. Low SES children manifest relatively high rates of failure from the very lowest grades (Battin-Pearson et al. 2000), and their attainments remain lower than average across the school years (Purcell-Gates \& Dahl 1991). They demonstrate poorer vocabulary and reading compared with their mainstream, middle-class peers (Au 1998; Snow et al. 1991). Reading accuracy, reading comprehension, spelling and writing abilities are also weaker among children of low SES background (Chevrot, Nardy \& Barbu 2011).

Where do these differences come from? In the past, the linguistic perspective on differential language performance and knowledge in socio-economic contexts was anchored more in sociolinguistic questions of sociolect and dialect than in clinical deficiencies (Furrow \& Nelson 1984; Labov \& Harris 1986; Williamson 1986). Yet a torrent of research work points at genuine, early emerging effects of SES background on language abilities (Fernald, Marchman \& Weisleder 2013; Fish \& Pinkerman 2003). SES has been found to affect various linguistic domains, from sensitivity to the phonetic structure of spoken words (Blachman et al 1999; Nittrouer 1996), through lexical development (Arriaga et al. 1998; Qi et al. 2006), inflectional and derivational morphological abilities (Ravid 1995; Ravid \& Schiff 2006; Schiff \& Ravid 2012) and discourse production (Price, Roberts \& Jackson 2006) to acquisition of figurative language (Berman \& Ravid 2010) and theory of mind (Cutting \& Dunn 1999; Shatz et al. 2003). These deficiencies are related both to the development of crucial brain regions (Kishiyama et al. 2009; Noble, Norman \& Farah 2005) as well as to important cognitive functions such as executive control (D’Angiulli et al. 2008; Engel, Santos \& Gathercole 2008; Farah et al. 2006).

Recent technological advancements in studying child and adult language and approaches such as Corpus Linguistics, discussed above, are highly relevant to this issue. Recently, psycholinguistic studies have shown that amount and quality of linguistic input addressed to children have a connection with the SES background of mothers (Hoff, 2003, 2006), with scarcer input resulting in a slower and less effective rate of language acquisition (Black, Peppé \& Gibbon 2008; Ginsborg 2006).

Moreover, from infancy on, children from low SES backgrounds are exposed to largely directive instructions rather than to elaborative and enriching language (Hoff 2013; Ninio 1980; Rowe 2008; Shimpi, Fedewa \& Hans 2012), they fail to receive appropriate linguistic and communicative mediation from their surroundings, they are less actively involved as conversational partners in family get-togethers, and they engage less than their more advantaged peers in joint book-reading and interactive writing with their parents (Anderson \& Stokes 1984; Aram \& Biron 2004).

To illustrate the critical impact of SES background on children's linguistic development, consider Figures 2-3. They represent some findings from a recent study comparing Hebrew Child Directed 


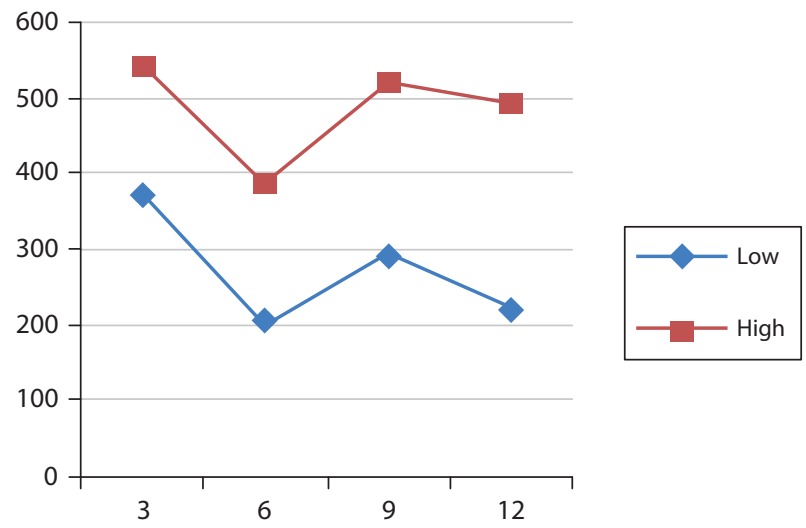

2a. Word types In Child Directed Speech to infants 3-12 months

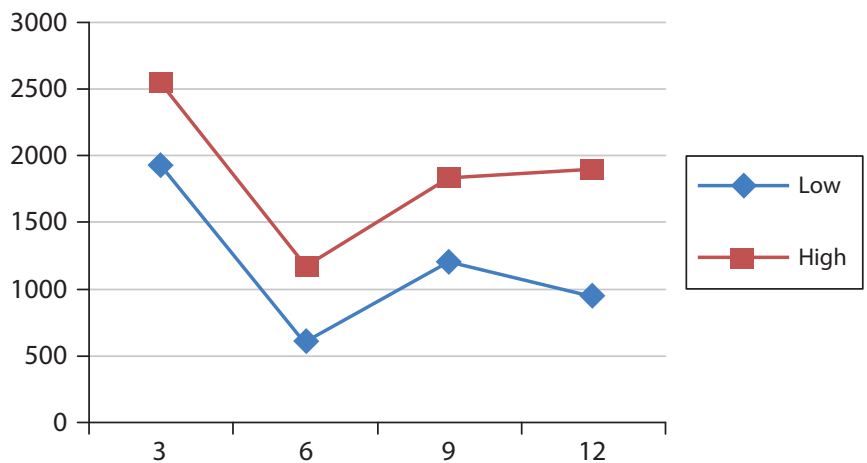

2b. Word tokens In Child Directed Speech to infants 3-12 months

Figure 2. CDS word types and tokens at each data point ( 3 months, 6 months, 9 months, 12 months) in high-SES and low-SES mothers (Ravid, Peleg \& Peleg, 2013)

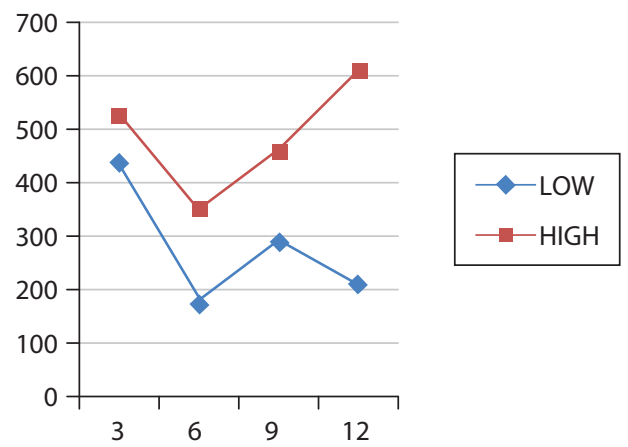

Figure 3. Percentage of utterances with fine-tuning at each data point ( 3 months, 6 months, 9 months, 12 months) in CDS by high-SES and low-SES mothers (Ravid, Peleg \& Peleg, 2013) 
Speech by two mothers to their respective infants in the first year of life - a low SES and a high SES mother. All variables - familial and social (e.g., child sex, order of siblings in the family) - were carefully controlled for in selecting the mothers for this comparison. Their speech was sampled when their babies were 3, 6, 9 and 12 months old respectively (Ravid, Peleg \& Peleg 2013). Figure 2 shows the number of word types and tokens the infants were exposed to: at each data point the lowSES baby heard a lesser amount of words, and at one year of age, when linguistic input is critical given early word acquisition, a wider gap opens between the two mothers. In fact, this study showed that overall the high-SES infant heard 1.7 more speech than the low-SES one. Figure 3 compares the relative amount of utterances fine-tuned to the infant's developmental stage (slower, clearer, with varying pitch and emphasis, etc.): and again, not only does the high-SES mother produce more finetuned speech at all data points, this important behavior, facilitating babies' word learning, increases when the baby is one year old, when first words emerge; whereas the low-SES mother's fine tuning decreases. This was but a tiny sample of the diverse linguistic analyses carried out on the transcriptions of the two mothers, which all clearly pointed at the same direction: the infant from high-SES background was exposed to more and more qualitative CDS, than her low-SES peer.

\section{Bilingualism}

In the same context of ambient language structure, bi- and multilingualism constitute our final example of linguistics benefitting CD research and treatment. Bilingualism is neither a detrimental nor a disordered condition. On the contrary - growing up in two or more languages has long been a topic of linguistic and psychological work (De Houwer 2009; Hoff \& McCardle 2006), with a general consensus that it benefits bi- and multi-lingual individuals across the life span not only linguistically but also cognitively (Bialystok 2001; Grosjean \& Li 2013; Hyltenstam \& Obler 1989). Much of the debate in the domain has been devoted to the question of a window of age or a critical period in learning more than one language (DeKeyser, Alfi-Shabtay \& Ravid 2010; Newport 1990; Ortega 2013). Two interesting, diametrically opposed, questions continuously challenge CD specialists in this context, with possible answers residing in current linguistic research. They can be summed up as "How much is enough?" and "can it be risky?". The first question involves reaching native, or near-native, fluency and proficiency in the languages learned simultaneously or sequentially. CD researchers working in language acquisition are often tasked with the practical question of learning more than one language. They are thus interested in what enables some learners to make maximal attainments in bilingual learning despite the diminished input contexts for the acquisition of each language (Gathercole \& Hoff 2007). The role of linguistic input in multiple language acquisition has gained attention and significance with the advent of systematic studies of the complexity of bilingual situations, which are fraught with conflicting factors of language knowledge and usage and of social settings (Abugov \& Ravid 2013; De Houwer 2011; Gathercole et al. 2010). Beyond individual differences, the answer can probably be found in current investigations of the amount and types of linguistic input, communicative experience and diversity of opportunities for language exposure and usage in each of the languages learned (Gathercole 2010; Hoff et al. 2012; McCardle \& Hoff 2006).

A second question concerns another facet of bilingualism where linguistics has an important say for $\mathrm{CD}$ researchers and therapists is the question of language disability in children growing up in bilingual environments (Armon-Lotem in press; Paradis 2010). This is the overlap between certain attributes of language impairment and bilingualism: For example, children learning English as a second language were shown to perform similar errors as monolingual children with linguistic impairment (Paradis, 2005), raising interesting questions on the possible interface of developmental trajectories in bilingualism and language impairment. This similarity has important clinical implications for the identification of children suffering from language disorder in communities where the 
absence of certain grammatical morphemes (e.g., -s) might be the norm rather than the marker of a disorder (Pruitt \& Oetting, 2009; Washington \& Craig 2004).

\section{Conclusion}

A journal article, even one that purports to review the interface between two venerable fields of scholarly investigation, cannot aspire to achieve more than a limited overview of its domain of inquiry. The current article aimed at establishing points of congruity between two independent though related disciplines - the theoretical and empirical study of linguistics, on the one hand, and the clinical field of CD, on the other. We hope to have shown that they can both feed each other's need for an evidence-based, insightful understanding of the interface between language and cognition, especially through their shared interest in developmental aspects of language learning and processing and the impact of different disorders and environmental conditions on linguistic development. We have also pointed out the increase in what is now thought to be areas of linguistic relevance such as discourse and written language, and to what extent this can teach us about language, communication and their disorders.

\section{References}

Abugov, N. \& Ravid, D. 2013. Assessing Yiddish plurals in acquisition: Impacts of bilingualism. In Bilinguals and Assessment: State of the Art Guide to Issues and Solutions from around the World, V.C.M. Gathercole (ed.), 90-110. Bristol: Multilingual Matters.

Ahissar, M. 2007. Dyslexia and the anchoring-deficit hypothesis. Trends in Cognitive Sciences 11: 458-465. DOI: 10.1016/j.tics.2007.08.015

Anderson, A. \& Stokes, S. 1984. Social and institutional influences on the development and practice of literacy. In Awakening to Literacy, H. Goelman, A. Oberg \& F. Smith (eds), 24-37. Exeter NH: Heinemann.

Aram, D. \& Biron, S. 2004. Joint storybook reading and joint writing interventions among low SES preschoolers: Differential contributions to early literacy. Early Childhood Research Quarterly 19: 588-610. DOI: 10.1016/j.ecresq.2004.10.003

Aram, D., Korat, O. \& Levin, I. 2006. Maternal mediation in a young child's writing activity: A sociocultural perspective. In Handbook of Orthography and Literacy, R.M. Joshi \& P.G. Aaron (eds), 709-734. Mahwah NJ: Lawrence Erlbaum Associates.

Arriaga, R.I., Fenson, L., Cronan, T. \& Pethick, S.J. 1998. Scores on the MacArthur communicative development inventory of children from low- and middle-income families. Applied Psycholinguistics 19: 209223. DOI: $10.1017 /$ S0142716400010043

Armon-Lotem S. In press. Between L2 and SLI: Inflections and prepositions in the Hebrew of bilingual children with TLD and monolingual children with SLI. Journal of Child Language.

$\mathrm{Au}, \mathrm{K} .1998$. Social constructivism and the school literacy learning of students of diverse backgrounds. Journal of Literacy Research 30: 297-319. DOI: 10.1080/10862969809548000

Baayen, R.H. 2008. Analyzing Linguistic Data. Cambridge: CUP. DOI: 10.1017/CBO9780511801686

Bar-On, A. 2011. Linguistic processes in reading non-voweled Hebrew. In Literacy and Language, O. Korat \& D. Aram (eds), 148-165. Jerusalem: Magnes (in Hebrew).

Bar-On, A. \& Ravid, D. 2011. Morphological decoding in Hebrew pseudo words: A developmental study. Applied Psycholinguistics 32: 553-581. DOI: 10.1017/S014271641100021X

Battin-Pearson, S., Newcomb, M.D., Abbott, R.D., Hill, K.G., Catalano, R.F. \& Hawkins, J.D. 2000. Predictors of early high school drop-out: A test of five theories. Journal of Educational Psychology 92: 568-582. DOI: $10.1037 / 0022-0663.92 .3 .568$

Berman, R.A. 2004. Between emergence and mastery: The long developmental route of language acquisition. In Language Development across Childhood and Adolescence, R.A. Berman (ed.), 9-34. Amsterdam: John Benjamins. DOI: 10.1075/tilar.3 
Berman, R.A. (ed.). 2005. Journal of Pragmatics 37(2). Special issue on Developing Discourse Stance across Adolescence.

Berman, R.A. 2008. The psycholinguistics of developing text construction. Journal of Child Language 35: 735-771. DOI: 10.1017/S0305000908008787

Berman, R.A. \& Nir-Sagiv, B. 2010. The lexicon in speech-writing differentiation: Developmental perspectives. Written Language and Literacy 13: 181-203. DOI: 10.1075/wll.13.2.01ber

Berman, R.A. \& Ravid, D. 2008. Becoming a literate language user: Oral and written text construction across adolescence. In Cambridge Handbook of Literacy, D.R. Olson \& N. Torrance (eds), 92-111. Cambridge: CUP.

Berman, R.A. \& Ravid, D. 2010. Interpretation and recall of proverbs in three pre-adolescent populations. First Language 30: 155-173. DOI: 10.1177/0142723709359246

Berman R. A. \& Slobin, D.I. 1994. Relating Events in Narrative: A Crosslinguistic Developmental Study. Hillsdale NJ: Lawrence Erlbaum Assiocates.

Berman, R.A., Nayditz, R. \& Ravid, D. 2011. Linguistic diagnostics of written texts in two school-age populations. Written Language and Literacy 14: 161-187. DOI: 10.1075/wll.14.2.01ber

Berninger, V.W., Abbott, R.D., Thomson, J., Wagner, R., Lee Swanson, H., Wijsman, E.M. \& Raskind, W. 2006. Modeling phonological core deficits within a working memory architecture in children and adults with developmental dyslexia. Scientific Studies of Reading 10: 165-198. DOI: 10.1207/s1532799xssr1002_3

Bernstein, B. 1960. Aspects of language and learning in the genesis of the social process. Journal of Child Psychology and Psychiatry 1: 313-324. DOI: 10.1111/j.1469-7610.1960.tb02004.x

Berwick, R., Pietroski, P., Yankama, B. \& Chomsky, N. 2011. Poverty of the stimulus revisited. Cognitive Science 35: 1207-1242. DOI: 10.1111/j.1551-6709.2011.01189.x

Bialystok, E. 2001. Bilingualism in Development: Language, Literacy, and Cognition. Cambridge: CUP. DOI: 10.1017/CBO9780511605963

Bishop, D. 2009. Specific language impairment as a language learning disability. Child Language Teaching and Therapy 25: 163-165. DOI: 10.1177/0265659009105889

Bishop, D. \& Norbury, C.F. 2008. Speech and language impairments. In Rutter's Child and Adolescent Psychiatry, A. Thapar, M. Rutter, D. Bishop, D. Pine, S.M. Scott, J. Stevenson \& E. Taylor (eds), 782-801. Oxford: Wiley-Blackwell. DOI: 10.1002/9781444300895.ch47

Bishop, D.V.M. \& Snowling, M.J. 2004. Developmental dyslexia and specific language impairment: Same or different? Psychological Bulletin 130: 858-886. DOI: 10.1037/0033-2909.130.6.858

Blachman, B.A., Tangel, D., Ball, E.W., Black, R. \& Mcgraw, C.K. 1999. Developing phonological awareness and word recognition skills: A two-year intervention with low-income, inner-city children. Reading and Writing 11: 239-273. DOI: 10.1023/A:1008050403932

Black, E., Peppé, S. \& Gibbon, F. 2008. The relationship between socio-economic status and lexical development. Clinical Linguistics and Phonetics22: 259-265. DOI: 10.1080/02699200801918887

Bradley, R.H. \& Corwyn, R.F. 2002. Socioeconomic status and child development. Annual Review of Psychology 53: 371-399. DOI: 10.1146/annurev.psych.53.100901.135233

Bresnan, J. 2007. Is syntactic knowledge probabilistic? Experiments with the English dative alternation. In Roots: Linguistics in Search of its Evidential Base, S. Featherston \& W. Sternefeld (eds), 75-96. Berlin: Mouton de Gruyter.

Bybee, J.L. 2006. Frequency of Use and the Organization of Language. Oxford: OUP.

Bybee, J.L. 2010. Language, Usage and Cognition. Cambridge: CUP. DOI: 10.1017/CBO9780511750526

Carlisle, J.F. 2000. Awareness of structure and meaning of morphologically complex words: Impact on reading. Reading and Writing 12: 169-190. DOI: 10.1023/A:1008131926604

Carruthers, P. 2008. Language in cognition. In The Oxford Handbook of Philosophy of Cognitive Science, E. Margolis, R. Samuels \& S. Stich (eds), 382-401. Oxford: OUP.

Castles, A. \& Coltheart, M. 2004. Is there a causal link from phonological awareness to success in learning to read? Cognition 91: 77-111. DOI: 10.1016/S0010-0277(03)00164-1

Catts, H.W. 1991. Early identification of dyslexia: Evidence from a follow-up study of speech-language impaired children. Annals of Dyslexia 41: 163-177. DOI: 10.1007/BF02648084 
Catts, H.W. \& Kamhi, A.G. 1999. Causes of reading disabilities. In Language and Reading Disabilities, H.W. Catts \& A.G. Kamhi (eds), 95-127. Needham Heights MA: Allyn \& Bacon.

Chevrot, J.-P., Nardy, A. \& Barbu, S. 2011. Developmental dynamics of SES-related differences in children's production of obligatory and variable phonological alternations. Language Sciences 33: 180-191. DOI: 10.1016/j.langsci.2010.08.007

Chiu, M.M. \& McBride-Chang, C. 2006. Gender, context, and reading: A comparison of students in 43 countries. Scientific Studies of Reading 10: 331-362. DOI: 10.1207/s1532799xssr1004_1

Chomsky, N. 1985. The Logical Structure of Linguistic Theory. Chicago IL: University of Chicago Press.

Chung, S. 2009. Are lexical categories universal? The view from Chamorro. Theoretical Linguistics 38: 1-56. DOI: $10.1515 / \mathrm{tl}-2012-0001$

Cinque, G. 2013. Cognition, universal grammar, and typological generalizations. Lingua 130: 50-65. DOI: 10.1016/j.lingua.2012.10.007

Cirrin, F.M. \& Gillam, R.B. 2008. Language intervention practices for school-age children with spoken language disorders: A systematic review. Language, Speech, and Hearing Services in Schools 39: 110-137. DOI: 10.1044/0161-1461(2008/012)

Clark, M.K. \& Kamhi, A.G. 2010. Language disorders (Child Language Disorders). In J.H. Stone \& M. Blouin (eds). International Encyclopedia of Rehabilitation. Avaliable online: http://cirrie.buffalo.edu/encyclope$\mathrm{dia} / \mathrm{en} / \mathrm{article} / 31 /$

Conti-Ramsden, G. 1999. Classification of children with Specific Language Impairment: Longitudinal considerations. Journal of Speech, Language, and Hearing Research 42: 1195-1204.

Coppens, K.M., Tellings, A., Verhoeven, L. \& Schreuder, R. 2013. Reading vocabulary in children with and without hearing loss: The roles of task and word type. Journal of Speech, Language and Hearing Research 56: 654-666. DOI: 10.1044/1092-4388(2012/11-0138)

Croft, W. 2003. Typology and Universals, 2nd edn. Cambridge: CUP.

Croft, W. \& Cruse, D.A. 2004. Cognitive Linguistics. Cambridge: CUP. DOI: 10.1017/CBO9780511803864

Cutting, A.L. \& Dunn, J. 1999. Theory of mind, emotion understanding, language, and family background: Individual differences and interrelations. Child Development 70: 853-865. DOI: 10.1111/14678624.00061

D’Angiulli, A., Herdman, A., Stapells, D. \& Hertzman, C. 2008. Children's event-related potentials of auditory selective attention vary with their socioeconomic status. Neuropsychology 22: 293-300. DOI: 10.1037/0894-4105.22.3.293

Dattner, E. In preparation. Mapping Hebrew dative constructions. Ms., Tel Aviv University.

Deacon, S.H., \& Kirby, J.R. 2004. Morphological awareness: Just "more phonological"? The roles of morphological and phonological awareness in reading development. Applied Psycholinguistics 25: 223-238. DOI: $10.1017 /$ S0142716404001110

De Houwer, A. 2009. Bilingual First Language Acquisition. Clevedon: Multilingual Matters.

De Houwer, A. 2011. Language input environments and language development in bilingual acquisition. Applied Linguistics Review 2: 221-240. DOI: 10.1515/9783110239331.221

DeKeyser, R., Alfi-Shabtay, I, \& Ravid, D. 2010. Cross-linguistic evidence for the nature of age effects in second language acquisition. Applied Psycholinguistics 31: 413-438. DOI: 10.1017/S0142716410000056

Derwing, B.L. 1992. Orthographic aspects of linguistic competence. In The Linguistics of Literacy, P. Downing, S. Lima \& M. Noonan (eds), 193-210. Amsterdam: John Benjamins.

De Villiers, J.G. 2002. Defining SLI: A linguistic perspective. In Language Competence across Populations: Toward a Definition of Specific Language Impairment, Y. Levy \& J. Schaeffer (eds), 425-447. Mahwah NJ: Lawrence Erlbaum Associates.

Dromi, E., Leonard, L.B. \& Shteiman, M. 1993. The grammatical morphology of Hebrew-speaking children with specific language impairment: Some competing hypotheses. Journal of Speech and Hearing Research 36: 760-771.

Edelman, S. \& Christianson, M. 2003. How seriously should we take minimalist syntax? Trends in Cognitive Sciences 7: 60-61. DOI: 10.1016/S1364-6613(02)00045-1 
Engel, P.M.J., Santos, F.H. \& Gathercole, S.E. 2008. Are working memory measures free of socioeconomic influence? Journal of Speech, Language, and Hearing Research 51: 1580-1587. DOI: 10.1044/1092$4388(2008 / 07-0210)$

Evans, N. \& Levinson, S. 2009. The myth of language universals: Language diversity and its importance for cognitive science. Behavioral and Brain Sciences 32: 429-448. DOI: 10.1017/S0140525X0999094X

Farah, M.J., Sherab, D.M., Savagea, J.H., Betancourta, L., Giannetta, J.M., Brodsky, N.L., Malmud, E.K. \& Hurt, H. 2006. Childhood poverty: Specific associations with neurocognitive development. Brain Research 1110: 166-174. DOI: 10.1016/j.brainres.2006.06.072

Fernald, A., Marchman, V.A. \& Weisleder, A. 2013. SES differences in language processing skill and vocabulary are evident at 18 months. Developmental Science 16: 234-248. DOI: 10.1111/desc.12019

Fish, M. \& Pinkerman, B. 2003. Language skills in low-SES rural Appalachian children: Normative development and individual differences, infancy to preschool. Applied Developmental Psychology 23: 539-565. DOI: 10.1016/S0193-3973(02)00141-7

Friedmann, N. 2013. Verb movement to C: From agrammatic aphasia to syntactic analysis. In Diagnosing Syntax: Perspectives, Procedures and Tools, L. Cheng \& N. Corver (eds), 75-86. Oxford: OUP. DOI: 10.1093/acprof:oso/9780199602490.003.0004

Friedmann, N. \& Novogrodsky, R. 2004. The acquisition of relative clause comprehension in Hebrew: A study of SLI and normal development. Journal of Child Language 31: 661-681. DOI: 10.1017/ S0305000904006269

Frost, R. 2012. Towards a universal model of reading. Behavioral and Brain Sciences 35: 263-279. DOI: $10.1017 /$ S0140525X11001841

Furrow, D. \& Nelson, K. 1984. Environmental correlates of differences in language acquisition. Journal of Child Language 11: 523-534. DOI: 10.1017/S0305000900005936

Gaab, N., Gabrieli, J.D.E., Deutsch G. K., Tallal, P., \& Temple P. E. 2007. Neural correlates of rapid auditory processing are disrupted in children with developmental dyslexia and ameliorated with training: An fMRI study. Restorative Neurology and Neuroscience 25: 295-310.

Gabay, Y., Schiff. R. \& Vakil.E. 2012. Dissociation between online and offlinelearning in developmental dyslexia. Journal of Clinical and Experimental Neuropsychology 34: 279-288. DOI: 10.1080/13803395.2011.633499

Gathercole, V.C.M. 2010. Interactive influences in bilingual processing and development. International Journal of Bilingual Education and Bilingualism 13: 481-485. DOI: 10.1080/13670050.2010.488282

Gathercole, V.C.M. \& Hoff, E. 2007. Input and the acquisition of language: Three questions. In Blackwell Handbook of Language Development, E. Hoff \& M. Shatz (eds), 107-127. Oxford: Blackwell. DOI: 10.1002/9780470757833.ch6

Gathercole, V.C.M., Thomas, E.M., Jones, L., Guasch, N.V., Young, N. \& Hughes, E.K. 2010. Cognitive effects of bilingualism: Digging deeper for the contributions of language dominance, linguistic knowledge, socio-economic status and cognitive abilities. International Journal of Bilingual Education and Bilingualism 13: 617-664. DOI: 10.1080/13670050.2010.488289

Gibson, E. \& Fedorenko, E. 2013. The need for quantitative methods in syntax and semantics research. Language and Cognitive Processes 281(2): 88-124. DOI: 10.1080/01690965.2010.515080

Ginsborg, J. 2006. The effects of socio-economic status on children's language acquisition and use. In Language and Social Disadvantage: Theory into Practice, J. Clegg \& J. Ginsborg (eds), 9-27. London: Wiley \& Sons.

Goodluck, H. \& Zweig, E. 2013. Introduction: Formal vs. processing explanations of linguistic phenomen. Language and Cognitive Processes 28: 1-8. DOI: 10.1080/01690965.2012.718087

Goodwin, C.J. 2005. Research in Psychology: Methods and Design. New York NY: John Wiley.

Graesser, A.C. \& McNamara, D.S. 2011. Computational analyses of multilevel discourse comprehension. Topics in Cognitive Science 2: 371-398. DOI: 10.1111/j.1756-8765.2010.01081.x

Gries, S.T. \& Stefanowitsch, A. (eds). 2007. Corpora in Cognitive Linguistics: Corpus-based Approaches to Syntax and Lexis. Berlin: Mouton de Gruyter.

Grosjean, F. \& Li, P. 2013. The Psycholinguistics of Bilingualism. Malden MA: Wiley-Blackwell.

Harris, C.L. 2003. Language and cognition. Encyclopedia of Cognitive Science. London: MacMillan. 
Hart, B. \& Risley, R.T. 1995. Meaningful Differences in the Everyday Experience of Young American Children. Baltimore MD: Paul H. Brookes.

Haspelmath, M. 2012. Escaping ethnocentrism in the study of word-class universals. Theoretical Linguistics 38: 91-102. DOI: 10.1515/tl-2012-0004

Herzberg, O. 2010. Early language development in Hebrew-speaking children with cochlear implants compared with their normally hearing peers. $\mathrm{PhD}$ dissertation, Tel Aviv and Antwerp Universities.

Hill, E.L. 2001. Non-specific nature of specific language impairment: A review of the literature with regard to concomitant motor impairments. International Journal of Language and Communication Disorders 36: 149-171. DOI: $10.1080 / 13682820010019874$

Hoff, E. 2003. The specificity of environmental influence: Socioeconomic status affects early vocabulary development via maternal speech. Child Development 74: 1368-1378. DOI: 10.1111/1467-8624.00612

Hoff, E. 2006. Language experience and language milestones during early childhood. In Handbook of Early Childhood Development, D. Phillips \& K. McCartney (eds), 233-251. Oxford: Blackwell. DOI: 10.1002/9780470757703.ch12

Hoff, E. 2013. Interpreting the early language trajectories of children from low-SES and language minority homes: Implications for closing achievement gaps. Developmental Psychology 49: 4-14. DOI: 10.1037/ a0027238

Hoff, E. \& McCardle, P. 2006. Childhood bilingualism research: An introduction. In Childhood Bilingualism: Research on Infancy through School Age, P. McCardle \& E. Hoff (eds), vii-x. Clevedon: Multilingual Matters.

Hoff, E., Core, C., Place, S., Rumiche, R., Señor, M. \& Parra, M. 2012. Dual language exposure and early bilingual development. Journal of Child Language 39: 1-27. DOI: 10.1017/S0305000910000759

Hofmeister, P.T., Jaeger, F., Arnon, I., Sag, I.A. \& Snider, N. 2013. The source ambiguity problem: Distinguishing the effects of grammar and processing on acceptability judgments. Language and Cognitive Processes 28: 48-87. DOI: 10.1080/01690965.2011.572401

Houston, D.M. 2002. What infants learn about native sound organization during their first year and what may happen if they don't. Antwerp Papers in Linguistics 102: 11-21.

Hyltenstam, K. \& Obler, L. K. (eds). 1989. Bilingualism across the Lifespan. Cambridge: CUP. DOI: 10.1017/ CBO9780511611780

Jarmulowicz, L. \& Taran, V.L. 2013. Lexical morphology: Structure, process, and development. Topics in Language Disorders 33: 57-72. DOI: 10.1097/TLD.0b013e318280f5c0

Joanisse, M.F. \& Seidenberg, M.S. 1998. Specific language impairment: A deficit in grammar or processing? Trends in Cognitive Sciences 2: 240-247. DOI: 10.1016/S1364-6613(98)01186-3

Kertész, A. \& Rákosi, C. 2012. Data and Evidence in Linguistics: A Plausible Argumentation Model. Cambridge: CUP. DOI: 10.1017/CBO9780511920752

Kishiyama, M.M., Boyce, W.T., Jimenez, A.M., Perry, L.M. \& Knight, R.T. 2009. Socioeconomic disparities affect prefrontal function in children. Journal of Cognitive Neuroscience 21: 1106-1115. DOI: 10.1162/ jocn.2009.21101

Labov, W. \& Harris, W. 1986. De facto segregation of black and white vernaculars. In Diversity and Diachrony, D. Sankoff (ed.), 1-24. Amsterdam: John Benjamins.

Lakoff, G. 1991. Cognitive linguistics versus generative linguistics: How commitments influence results. Language and Communication 11: 53-62. DOI: 10.1016/0271-5309(91)90018-Q

Langacker, R.W. 1987. Foundations of Cognitive Grammar: Theoretical Prerequisites, Vol. 1. Stanford CA: Stanford University Press.

Leonard, L.B. 2009. Is expressive language disorder an accurate diagnostic category? American Journal of Speech-Language Pathology 18: 115-123. DOI: 10.1044/1058-0360(2008/08-0064)

Leonard, L.B. 2010. Specific language impairment. In The Cambridge Encyclopedia of the Language Sciences, P. Hogan (ed.), 785-786. Cambridge: CUP.

Leonard, L.B. \& Deevy, P. 2006. Cognitive and linguistic issues in the study of children with specific language impairment. In Handbook of Psycholinguistics, 2nd edn, M. Traxler \& M.A. Gernsbacher (eds), 1143-1171. London: Academic Press. DOI: 10.1016/B978-012369374-7/50031-6 
Levshina, N., Geeraerts, D. \& Speelman, D. 2013. Mapping constructional spaces: A contrastive analysis of English and Dutch analytic causatives. Linguistics 514: 825-854.

Liberman, I.Y., Shankweiler, D., Fischer, F.W., \& Carter, B. 1974. Explicit syllable and phoneme segmentation in the young child. Journal of Experimental Child Psychology 18: 201-212. DOI: 10.1016/00220965(74)90101-5

Mackie, C., Dockrell, J.E. \& Lindsay, G. 2013. An evaluation of the written texts of children with SLI: The contributions of oral language, reading and phonological short-term memory. Reading and Writing 26: 865-888. DOI: $10.1007 / \mathrm{s} 11145-012-9396-1$

McCarthey, S. 1997. Connecting home and school literacy practices in classrooms with diverse populations. Journal of Literacy Research 29: 143-182. DOI: 10.1080/10862969709547955

McArthur, G.M., Ellis, D. \& Atkinson, C. 2009. Atypical brain responses to sounds in children with language and reading impairments. Developmental Science 12: 768-783. DOI: 10.1111/j.1467-7687.2008.00804.x

McCardle, P. \& Hoff, E. 2006. An agenda for research on childhood bilingualism. In Childhood Bilingualism: Research on Infancy through School Age, P. McCardle \& E. Hoff (eds), 157-165. Clevedon: Multilingual Matters.

McClelland, J.L., Botvinick, M.M., Noelle, D.C., Plaut, D.C., Rogers, T.T., Seidenberg, M.S. \& Smith, L.B. 2010. Letting structure emerge: Connectionist and dynamical systems approaches to cognition. Trends in Cognitive Sciences 14: 348-356. DOI: 10.1016/j.tics.2010.06.002

McNamara, D.S., Crossley, S.A. \& McCarthy, P.M. 2010. Linguistic features of writing quality. Written Communication 27: 57-86. DOI: 10.1177/0741088309351547

Morgan, W. 1896. A case of congenital word blindness. British Medical Journal 2: 1378. DOI: 10.1136/ bmj.2.1871.1378

Natriello, G., McDill, E. \& Pallas, A. 1990. Schooling Disadvantaged Children: Racing against Catastrophe. New York NY: Teachers' College.

Newport, E.L. 1990. Maturational constraints on language learning. Cognitive Science 14: 11-28. DOI: $10.1207 /$ s15516709cog1401_2

Nelson, H.D., Bougatsos, C. \& Nygren, P. 2008. 2001 US Preventive Services Task Force. Universal newborn hearing screening: Systematic review to update the 2001 US Preventive Services Task Force Recommendation. Pediatrics 122: 266-276. DOI: 10.1542/peds.2007-1422

Neuman, S. \& Celano, D. 2001. Access to print in low-income and middle-income communities. Reading Research Quarterly 36: 8-26. DOI: 10.1598/RRQ.36.1.1

Nicholas, J.G. \& Geers, A.E. 2007. Will they catch up? The role of age at cochlear implantation in the spoken language development of children with severe-profound hearing loss. Journal of Speech, Language and Hearing Research 50: 1048-1062. DOI: 10.1044/1092-4388(2007/073)

Ninio, A. 1980. Picture-book reading in mother-infant dyads belonging to two subgroups in Israel. Child Development 51: 587-590. DOI: 10.2307/1129299

Nippold, M. 2007. Later Language Development: School-age Children, Adolescents, and Young Adults, 3rd edn. Austin TX: Pro-ed.

Nippold, M.A., Mansfield, T.C. Billow, J.L. \& Tomblin, J.B. 2009. Expository discourse in adolescents with language impairments: Examining syntactic development. American Journal of Speech-Language Pathology 17: 356-366. DOI: 10.1044/1058-0360(2008/07-0049)

Nittrouer, S. 1996. The relation between speech perception and phonemic awareness: Evidence from low-SES children and children with chronic OM. Journal of Speech and Hearing Research 39: 1059-1071.

Noble, K.G., Norman, M.F. \& Farah, M.J. 2005. Neurocognitive correlates of socioeconomic status in kindergarten children. Developmental Science 8: 74-87. DOI: 10.1111/j.1467-7687.2005.00394.x

Olson, D. 1994. The World on Paper. Cambridge: Cambridge University Press.

Ortega, L. 2013. SLA for the 21st century: Disciplinary progress, transdisciplinary relevance, and the bi/multilingual turn. Language Learning 63: 1-24. DOI: 10.1111/j.1467-9922.2012.00735.x

Paradis, J. 2005. Grammatical morphology in children learning English as a second language: Implications of similarities with specific language impairment. Language, Speech and Hearing Services in the Schools 36: 172-187. DOI: 10.1044/0161-1461(2005/019) 
Paradis, J. 2010. The interface between bilingual development and specific language impairment. Applied Psycholinguistics 31: 227-252. DOI: 10.1017/S0142716409990373

Paul, R. 2007. Language Disorders from Infancy through Adolescence: Assessment and Intervention, 3rd edn. St. Louis MO: Mosby-Year Book.

Paul, P. \& Quigley, S.P. 1994. Language and Deafness. San Diego CA: Singular.

Perfetti, C.A. 2003. The universal grammar of reading. Scientific Studies of Reading 7: 3-24. DOI: 10.1207/ S1532799XSSR0701_02

Perfetti, C.A. 2011. Phonology is critical in reading: But a phonological deficit is not the only source of low reading skills. In Explaining Individual Differences in Reading, S.A. Brady, D. Braze \& C.A. Fowler (eds), 153-171. New York NY: Routledge.

Phillips, C. 2010. Should we impeach armchair linguists? In Japanese-Korean Linguistics, S. Iwasaki, H. Hoji, P. Clancy \& S.-O. Sohn (eds), 49-64. Stanford CA: CSLI.

Piantadosi, S. \& Gibson, E. In press. Quantitative standards for absolute linguistic universals. Cognitive Science.

Price, J.R., Roberts, J.E. \& Jackson, S.C. 2006. Structural development of the fictional narratives of African American preschoolers. Language, Speech, and Hearing Services in Schools 37: 178-190. DOI: 10.1044/0161-1461(2006/020)

Pruitt, S. \& Oetting. J. 2009. Past tense marking by African American English-speaking children reared in poverty. Journal of Speech, Language and Hearing Research 52: 2-15. DOI: 10.1044/1092-4388(2008/070176)

Purcell-Gates, V. \& Dahl, K.L. 1991. Low-SES children's success and failure at early literacy learning in skillsbased classrooms. Journal of Reading Behavior 23: 1-34.

Qi, C.H., Kaiser, A.P., Milan, S. \& Hancock, T. 2006. Language performance of low-income African American and European American preschool children on the PPVT-III. Language, Speech, and Hearing Services in Schools 37: 5-16. DOI: 10.1044/0161-1461(2006/002)

Ravid, D. 1995. Language Change in Child and Adult Hebrew: A Psycholinguistic Perspective. Oxford: OUP.

Ravid, D. 2005. Emergence of linguistic complexity in written expository texts: Evidence from later language acquisition. In Perspectives on Language and Language Development, D. Ravid \& H. Bat-Zeev Shyldkrot (eds), 337-355. Dordrecht: Kluwer. DOI: 10.1007/1-4020-7911-7_25

Ravid, D. 2006. Semantic development in textual contexts during the school years: Noun scale analyses. Journal of Child Language 33: 791-821. DOI: 10.1017/S0305000906007586

Ravid, D. 2012. Spelling Morphology: The Psycholinguistics of Hebrew Spelling. Dordrecht: Springer. DOI: 10.1007/978-1-4419-0588-8

Ravid, D. In press. Syntactic complexity in discourse production across different text types. In TextStructuring: Across the Line of Speech and Writing Variation, C. Bolly \& L. Degand (eds). Louvain-laNeuve: Presses Universitaires de Louvain.

Ravid, D. \& Berman, R. 2009. Developing linguistic register in different text types. Pragmatics and Cognition17: 108-145. DOI: 10.1075/pc.17.1.04rav

Ravid, D. \& Berman, R. 2010. Developing noun phrase complexity at school-age: A text-embedded crosslinguistic analysis. First Language 30: 3-26. DOI: 10.1177/0142723709350531

Ravid, D. \& Levie, R. 2010. Adjectives in the development of text production: Lexical, morphological and syntactic analyses. First Language 30: 27-55. DOI: 10.1177/0142723709350529

Ravid, D. \& Schiff, R. 2006. Morphological abilities in Hebrew-speaking gradeschoolers from two socioeconomic backgrounds: An analogy task. First Language 26: 381-402. DOI: 10.1177/0142723706064828

Ravid, D. \& Tolchinsky, L. 2002. Developing linguistic literacy: A comprehensive model. Journal of Child Language 29: 419-448.

Ravid, D., Dromi, E. \& Kotler, P. 2009. Linguistic complexity in school-age text production: Expository vs. mathematical discourse. In Expository Discourse in Children, Adolescents, and Adults: Development and Disorders, M.A. Nippold \& C.M. Scott (eds), 125-156. New York NY: Psychology Press.

Ravid, D., Levie, R. \& Avivi Ben-Zvi, G. 2003 The role of language typology in linguistic development: Implications for the study of language disorders. In Language Competence across Populations: Toward a 
Definition of Specific Language Impairment, Y. Levy \& J. Schaeffer (eds), 171-196. Mahwah NJ: Lawrence Erlbaum Associates.

Ravid, D., Peleg, S. \& Peleg, O. 2013. Maternal input to infants from two SES backgrounds. Paper presented at Pre- and Proto-morphology Meeting, University of Vienna, 21 February.

Raviv, T., Kessenich, M. \& Morrison, F.J. 2004. Mediational model of the association between socioeconomic status and three-year-old language abilities: The role of parenting factors. Early Childhood Research Quarterly 19: 528-547. DOI: 10.1016/j.ecresq.2004.10.007

Rice, M.L. \& Wexler, K. 1996. Toward tense as a clinical marker of specific language impairment in Englishspeaking children. Journal of Speech and Hearing Research 39: 1239-1257.

Rowland, C., Chang, F., Ambridge, B., Pine, J. \& Lieven, E. 2012. The development of abstract syntax: Evidence from structural priming and the lexical boost. Cognition 125: 49-63. DOI: 10.1016/j.cognition.2012.06.008

Rowe, M.L. 2008. Child-directed speech: Relation to socioeconomic status, knowledge of child development and child vocabulary skill. Journal of Child Language 35: 185-205. DOI: 10.1017/S0305000907008343

Schauwers, K., Gillis, S. \& Govaerts, P.J. 2008. The characteristics of prelexical babbling after cochlear implantation between 5 and 20 months of age. Ear and Hearing 29: 627-637. DOI: 10.1097/ AUD.0b013e318174f03c

Schiff, R. \& Ravid, D. 2007. Morphological analogies in Hebrew-speaking university students with dyslexia compared with typically developing gradeschoolers. Journal of Psycholinguistic Research 36(3): 237-253. DOI: $10.1007 / \mathrm{s} 10936-006-9043-6$

Schiff, R. \& Ravid, D. 2012. Linguistic processing in Hebrew-speaking children from low and high SES backgrounds. Reading and Writing 25: 1427-1448. DOI: 10.1007/s11145-011-9326-7

Schiff, R. \& Ravid, D. 2013. Morphological processing in Hebrew-speaking reading-disabled students. Journal of Learning Disabilities 46: 220-229. DOI: 10.1177/0022219412449425

Schütze, C. 2011a. Linguistic evidence and grammatical theory. Cognitive Science 2: 206-221. DOI: 10.1002/ wcs. 102

Schütze, C. 2011b. Grammaticality judgments. In The Cambridge Encyclopedia of the Language Sciences, P.C. Hogan (ed.), 349-350. Cambridge: CUP.

Schulte-Körne, G., Wolfgang-Deimel, C.A., Bartling, J. \& Remschmidt, H. 1998. Auditory processing and dyslexia: Evidence for a specific speech processing deficit. NeuroReport 9: 337-340 DOI: 10.1097/00001756199801260-00029

Scott, C. M. and Windsor, J., 2000. General language performance measures in spoken and written narrative and expository discourse of school-age children with language learning disabilities. Journal of Speech, Language, and Hearing Research, 43, 324-339.

Seymour, P.H. K., Aro, M., \& Erskine, J.M. 2003. Foundation literacy acquisition in European orthographies. British Journal of Psychology 94: 143-174. DOI: 10.1348/000712603321661859

Share, D.L. 2008. On the Anglocentricities of current reading research and practice: The perils of overreliance on an "outlier" orthography. Psychological Bulletin 134: 584-615. DOI: 10.1037/0033-2909.134.4.584

Share, D.L., \& Blum, P. 2005. Syllable splitting in literate and preliterate Hebrew speakers: Onsets and rimes or bodies and codas? Journal of Experimental Child Psychology 92: 182-202. DOI: 10.1016/j. jecp.2005.05.003

Shatz, M., Diesendruck, G., Martinez-Beck, I. \& Akar, D. 2003. The influence of language and socioeconomic status on children's understanding of false belief. Developmental Psychology 39: 717-729. DOI: 10.1037/0012-1649.39.4.717

Shimpi, P.M., Fedewa, A. \& Hans, S. 2012. Social and linguistic input in low-income African American mother-child dyads from 1 month through 2 years: Relations to vocabulary development. Applied Psycholinguistics 33: 781-798. DOI: 10.1017/S0142716411000567

Slobin, D.I. 1996. From "Thought and Language" to "Thinking for Speaking." In Rethinking Linguistic Relativity, J. Gumperz \& S. Levinson (eds), 70-96. Cambridge: CUP.

Snow, C.E., Barnes, W.S., Chandler, J., Goodman, I.F. \& Hemphill, L. 1991. Unfulfilled Expectations: Home and School Influences on Literacy. Cambridge MA: Harvard University Press. 
Snowling, M.J., Gallagher, A. \& Frith, U. 2003. Family risk of dyslexia is continuous: Individual differences in the precursors of reading skill. Child Development 74: 358-373. DOI: 10.1111/1467-8624.7402003

Sprouse, J. \& Almeida, D. 2013. The empirical status of data in syntax: A reply to Gibson and Fedorenko. Language and Cognitive Processes 28: 222-228. DOI: 10.1080/01690965.2012.703782

Sprouse, J., Schütze, C. \& Almeida, D. 2013. Assessing the reliability of journal data in syntax: Linguistic Inquiry 2001-2010. Lingua, 134, 219-248.

Stiles, J., Reilly, J., Levine, S.C., Trauner, D. \& Nass, R. 2012. Neural Plasticity and Cognitive Development: Insights from Children with Prenatal Brain Injury. Oxford: OUP.

Strömqvist, S. \& Verhoeven, L. (eds). 2004. Relating Events in Narrative, Vol. 2: Typological and Contextual Perspectives. Mahwah NJ: Lawrence Erlbaum Associates.

Sun, L. \& Nippold, M.A. 2012. Narrative writing in children and adolescents: Examining the literate lexicon. Language, Speech, and Hearing Services in Schools 43: 2-13. DOI: 10.1044/0161-1461(2011/10-0099)

Svirsky, M.A. 1999. Language development in children with profound and prelingual hearing loss, without cochlear implants. Annals of Otology, Rhinology and Laryngology 185: 99-100.

Swisher, L., Restrepo, M., Plante, E. \& Lowell, S.. 1995. Effect of implicit and explicit "rule" presentation on bound-morpheme generalization in specific language impairment. Journal of Speech and Hearing Research, 38: 168-173.

Tallal, P. 2004. Improving language and literacy is a matter of time. Nature Reviews Neuroscience 5: 721-728. DOI: $10.1038 / \mathrm{nrn} 1499$

Tily, H. \& Jaeger, T. 2011. Complementing quantitative typology with behavioral approaches: Evidence for typological universals. Linguistic Typology 15: 497-508. DOI: 10.1515/lity.2011.033

Tomasello, M. 2003. Constructing a Language: A Usage-Based Theory of Language Acquisition. Cambridge MA: Harvard University Press.

Van der Lely, H.K. 2005. Domain-specific cognitive systems: Insight from Grammatical-SLI. Trends in Cognitive Sciences 9: 53-59. DOI: 10.1016/j.tics.2004.12.002

Van der Lely, H.K., Jones, M. \& Marshall, C.R. 2011. Who did Buzz see someone? Grammaticality judgment of wh-questions in typically developing children and children with Grammatical-SLI. Lingua 121: 408-422. DOI: 10.1016/j.lingua.2010.10.007

Washington, J. \& Craig, H.K. 2004. A language screening protocol for use with young African American children in urban settings. American Journal of Speech-Language Pathology 13: 329-334. DOI: 10.1044/1058-0360(2004/033)

Williams, G.J., Larkin, R.F. \& Blaggan, S. 2013. Written language skills in children with specific language impairment. International Journal of Language and Communication Disorders 48: 160-171. DOI: $10.1111 / 1460-6984.12010$

Williamson, R. 1986. Formes connectives et cohésion textuelle dans le discours conversationnel d'enfants de différentes classes sociales dans le capitale mexicaine. In Diversity and Diachrony, David Sankoff (ed.), 333-346. Amsterdam: John Benjamins.

\section{Authors' addresses}

Dorit Ravid

Tel-Aviv University

doritr@post.tau.ac.il

Amalia Bar-On

Tel-Aviv University

amaliaba@zahav.net.il
Elitzur Dattner

Tel-Aviv University

elitzurd@gmail.com 